\title{
Controlling the Structure and Size of Au Nanocrystals by Annealing and lon Sputtering
}

Weixing Li, ${ }^{\dagger, t, \S}$ Yanbin Chen, ${ }^{\ddagger}$ Jiaming Zhang, ${ }^{\S}$ Lumin Wang, ${ }^{\dagger+\$}$ and Rodney C. Ewing, ${ }^{* \dagger, t, \S}$

${ }^{\dagger}$ Department of Materials Science and Engineering, ${ }^{\ddagger}$ Department of Nuclear Engineering and Radiological Sciences, and ${ }^{\S}$ Department of Earth and Environmental Sciences, University of Michigan, Ann Arbor, Michigan 48109, United States

\section{Supporting Information}

ABSTRACT: In situ thermal annealing was used for the first time to observe directly that $\mathrm{Au}$ nanoparticles, which were originally fully embedded in the near-surface region of $\mathrm{TiO}_{2}$, can be tailored into hemispheres exposed at the surface at elevated temperature. Precise control of the size of the $\mathrm{Au}$ hemispheres was achieved by subsequent low-energy ion sputtering. This method can be used to control the structure and size of a wide variety of nanoparticles in a matrix where surface structure and particle size are required to obtain specific material properties.

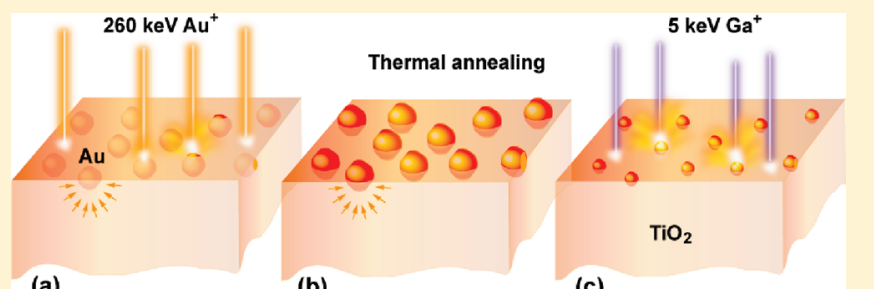

(a) (b) (c)

\section{INTRODUCTION}

Highly dispersed nanocrystals in a matrix have attracted increasing interest because of their potential use in a wide range of catalytic reactions ${ }^{1-6}$ as well as in biomedical, magnetic, and optical applications. ${ }^{7-11}$ However, the performance of these nanocomposites depends strongly on the size and structure of the nanocrystals. For example, bulk gold is chemically inert and a poor catalyst. However, when gold particles are smaller than $10 \mathrm{~nm}$ in diameter and deposited on selected oxides, they exhibit remarkable catalytic activity ${ }^{2}$ that strongly depends on the particle size. ${ }^{12}$ Because catalytic reactions occur at the interfaces around the perimeter of $\mathrm{Au}$ particles, ${ }^{13}$ it is important that the nanoparticles are exposed but also retain a strong contact with the surface (e.g., hemispherical $\mathrm{Au}$ nanoparticles deposited on $\left.\mathrm{TiO}_{2}\right){ }^{13} \mathrm{Sim}$ ilarly, $\mathrm{TiO}_{x}$ nanoparticles grown on a $\mathrm{Au}(111)$ substrate, as inverse catalysts, exhibit high performance in the water-gas shift reaction because of cooperative effects at the oxide-metal interface. ${ }^{1}$ For biomedical applications, $\mathrm{Fe}_{3} \mathrm{O}_{4}$ nanoparticles embedded in polystyrene nanospheres exhibit strong fluorescence emission in the visible range of the electromagnetic spectrum. ${ }^{10}$ The particle size must be controlled for these applications because it strongly affects the superparamagnetic state of the $\mathrm{Fe}_{3} \mathrm{O}_{4}$ nanoparticles. ${ }^{10,14}$ An obvious improvement in photocatalytic efficiency has also been reported in rutile $\mathrm{TiO}_{2}$, with $\mathrm{Ag}$ nanoparticles implanted near the surface. ${ }^{5}$ Therefore, the synthesis of nanocomposites for different applications requires the creation of nanoparticles with precise control of the particle size and strong, favorable contact with the supporting matrix.

As a widely used technique for the synthesis of nanocomposite materials, ion implantation has the main advantage that it can be used to exceed the equilibrium solubility limit for the metal in the dielectric matrix, ${ }^{15,16}$ as compared to that of other methods. ${ }^{12,17-21}$ Essentially any element in the periodic table can be implanted into the near surface region in most host materials. ${ }^{11,22-25}$ However, the change in the morphological and chemical properties of the oxide support can be very limited, especially when thermal treatment is performed after implantation. The surface treatment of powders by negative-ion implantation has also been reported. ${ }^{26,27}$ There are intense studies on controlling the precipitation location of the nanopariticles by tuning implantation parameters such as the ion energy, beam current, annealing temperature, and the use of negative ions or an electron-beam resist mask. ${ }^{11,22,23}$ Recent studies show that thermal annealing likely causes the formation of nanocrystals on the surface of the supporting matrix, ${ }^{28}$ which strongly favors many catalytic reactions. However, as a result of the thermally induced growth and coalescence, the average size of these particles is much larger than $10 \mathrm{~nm}$, making them less than ideal for this application. Furthermore, there have been no in situ observations of the thermal annealing behavior, despite the importance of this process to the understanding of the formation and growth of nanoparticles in a matrix. In this letter, we have directly observed the growth of half-embedded $\mathrm{Au}$ nanocrystals on the surface of crystalline $\mathrm{TiO}_{2}$ during the in situ thermal annealing of an implanted (260 keV Au${ }^{+}$ions) specimen with a TEM. The size of the Au nanocrystals has been precisely controlled by the sputtering of low-energy $\mathrm{Ga}^{+}$ ions $(5 \mathrm{keV})$ as compared to those for a typical ion implantation with higher energies (several tens to hundreds of $\mathrm{keV}$ ). The mechanisms for the formation, growth, and size control of Au nanocrystals on $\mathrm{TiO}_{2}$ have been discussed.

Received: October 13, 2011

Revised: November 23, 2011

Published: December 5, 2011 


\section{EXPERIMENTAL METHODS}

The $260 \mathrm{keV} \mathrm{Au}{ }^{+}$ions were implanted into the (001) plane of rutile $\mathrm{TiO}_{2}$ single crystals at room temperature using a Danfysik ion implanter. The ion fluence was $5 \times 10^{16} \mathrm{Au}^{+} / \mathrm{cm}^{2}$ with a beam current density of $\sim 2.0 \mu \mathrm{A} / \mathrm{cm}^{2}$. Two types of thermal annealing experiments on the implanted specimens were performed. Cross-sectional thin foils of implanted specimens, prepared by a standard polishing method for TEM analysis, were used for in situ thermal annealing experiments in a JEOL 3011 TEM equipped with a Gatan double-tilt hot-stage specimen holder heated to $800^{\circ} \mathrm{C}$. In parallel, ex situ thermal annealing of bulk specimens was performed in a muffle furnace at 800 - $\mathrm{C}$ for $1 \mathrm{~h}$. The externally annealed specimens were further investigated by TEM, atomic force microscopy (AFM), and scanning electron microscope (SEM) in order to study the distribution and contact structure of $\mathrm{Au}$ nanoparticles on $\mathrm{TiO}_{2}$ after annealing. AFM experiments were performed in tapping mode with a Nanoscope IIIa AFM. To control the particle size, the externally annealed specimens were sputtered by $5 \mathrm{keV} \mathrm{Ga}^{+}$ions with a beam current of $0.12 \mathrm{nA}$ and a modified area of $\sim 150 \mu \mathrm{m}^{2}$ in a FEI Nova NanoLab focused ion beam (FIB) operated in a vacuum of $2 \times 10^{7} \mathrm{mbar}$ at room temperature. The FIB angle of incidence was set close to the normal direction of the specimen. The gradual decrease in the size of $\mathrm{Au}$ nanoparticles was recorded in situ by an SEM attached to the FIB between the intervals of ion sputtering. The simulation was performed by SRIM $^{29}$ which is a widely used code for ion-matter interaction, with the densities of $\mathrm{Au}$ and $\mathrm{TiO}_{2}$ set as 19.32 and $4.25 \mathrm{~g} / \mathrm{cm}^{3}$, respectively.

\section{RESULTS AND DISCUSSION}

In situ thermal annealing has been previously utilized to observe the very different thermal annealing behavior of latent fission tracks in apatite and zircon directly. ${ }^{30,31}$ In this study, after implanting $260 \mathrm{keV} \mathrm{Au}{ }^{+}$ions into $\mathrm{TiO}_{2}$, we performed in situ thermal annealing by using cross-sectional thin foils of the implanted specimens in a TEM hot-stage holder at $800^{\circ} \mathrm{C}$ in order to observe the thermally induced nucleation and growth of $\mathrm{Au}$ particles in $\mathrm{TiO}_{2}$ directly (Figure 1). The implanted gold nanoparticles were fully embedded in the near-surface regions of $\mathrm{TiO}_{2}$ before thermal treatment (Figure 1a). Generally, the morphology of large gold nanoparticles is close to that of a sphere with an average diameter of $\sim 20 \mathrm{~nm}$, but some faceted features can be seen in the deeper portions of the large particles, confirming the crystalline nature of the nanoparticles. High-resolution TEM (HRTEM) images show that there are small particles embedded in the amorphous $\mathrm{TiO}_{2}$ layer with a diameter of 1 to $2 \mathrm{~nm}$ (not shown), which can be easily distinguished from the large particles. Once the temperature of the hot-stage stabilized at $800^{\circ} \mathrm{C}$ for $9 \mathrm{~min}$, the growth of gold nanoparticles is clear as the average size of large particles increases to $\sim 27 \mathrm{~nm}$ (Figure $1 \mathrm{~b}$ ). The large nanoparticles do not move, as directly observed during the in situ annealing. This contrasts with the higher mobility of the smaller particles. As a gold cluster absorbs the nearby gold atoms, its size gradually increases, which significantly hinders its mobility within the $\mathrm{TiO}_{2}$ crystalline matrix. The nanoparticles, which were fully embedded in the host before annealing, become halfembedded as they grow upward preferentially along the [111] directions of $\mathrm{TiO}_{2}$ by merging with the smaller and closest particles (or $\mathrm{Au}$ atoms), making the faceted features more obvious. After annealing times in excess of $21 \mathrm{~min}$, the growth rate of large particles decreases and the average size saturates at $\sim 29 \mathrm{~nm}$ (Figure 1c). After thermal annealing, the contrast of the implanted $\mathrm{TiO}_{2}$ layer is significantly enhanced, suggesting the recrystallization of the damaged layer.
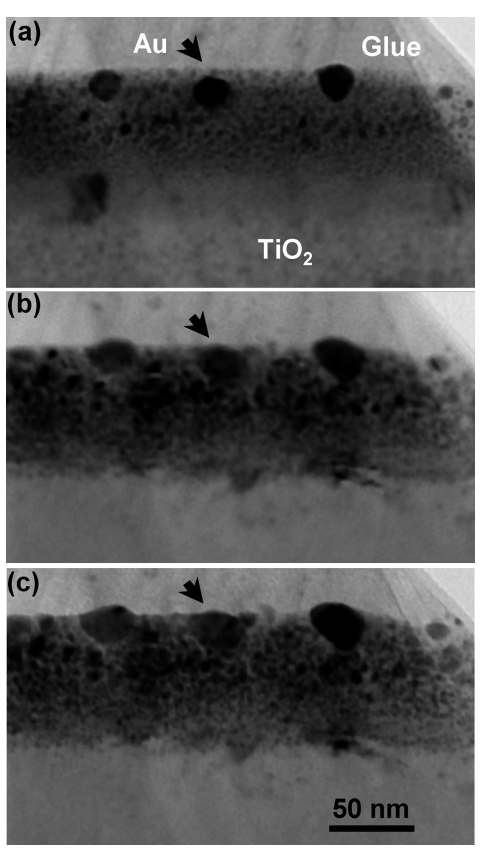

Figure 1. Cross-sectional TEM micrographs showing the in situ annealing of $260 \mathrm{keV} \mathrm{Au}{ }^{+}$ion-implanted $\mathrm{TiO}_{2}$ in a TEM hot stage at $800^{\circ} \mathrm{C}$. (a) Before heating and after (b) 9 and (c) $21 \mathrm{~min}$. As marked by the arrows, the Au clusters, which were initially fully embedded in $\mathrm{TiO}_{2}$, grow and become exposed on the surface.

The compositional and structural changes in the $\mathrm{Au}$ ions implanted $\mathrm{TiO}_{2}$ after in situ thermal annealing were compared to those after ex situ thermal annealing, where a bulk specimen was heated in a furnace at $800^{\circ} \mathrm{C}$ for $1 \mathrm{~h}$. After ex situ thermal annealing, the large particles originally embedded below the surface grow into half-embedded Au nanocrystals (average size $\sim 24 \mathrm{~nm}$ ) on the surface of $\mathrm{TiO}_{2}$ (Figure 2a). Similar to that observed in in situ thermal annealing, the crystallization of the implanted $\mathrm{TiO}_{2}$ host is evident from the enhanced contrast of the implanted layer after ex situ thermal annealing (Figure 2a). HRTEM images further confirm that both the gold particles and $\mathrm{TiO}_{2}$ host are crystalline (Figure $2 \mathrm{~b}$ ). A representative HRTEM image (Figure $2 \mathrm{~b}$ ) shows a faceted Au nanocrystal half-embedded on the crystalline $\mathrm{TiO}_{2}$ surface with orientation relationships of $\mathrm{Au}[111] \| \mathrm{TiO}_{2}[110]$ and $\mathrm{Au}(-220) \| \mathrm{TiO}_{2}(1-$ 11), similar to a previous TEM observation of $\mathrm{Au} / \mathrm{TiO}_{2}$ prepared by the sol-gel technique. ${ }^{17}$ The morphologies and distribution of $\mathrm{Au}$ nanoparticles on the surface of $\mathrm{TiO}_{2}$ were investigated by AFM (Figure 2c). The density of nanoparticles on the surface was estimated to be $1.38 \times 10^{10} / \mathrm{cm}^{2}$, indicating the average spacing between two particles to be $\sim 85 \mathrm{~nm}$. The average height of half-embedded $\mathrm{Au}$ particles is $\sim 10 \mathrm{~nm}$, consistent with that observed by TEM.

The formation of half-embedded Au particles is not due to the motion of the large particles toward the surface but is due to the absorption of small particles (or $\mathrm{Au}$ atoms) locally ${ }^{32,33}$ and the preferential growth of the large particles upward, as observed by TEM. The formation of a gold-depleted zone around the large particles (Figure $2 \mathrm{a}$ ) is attributed to the highly localized absorption of small particles around the large particles. This highly localized absorption also results in a direct correlation between the distribution of nanoscale particles as observed by TEM and the Au concentration profile as calculated by SRIM. ${ }^{29}$ Further discussion of the highly localized absorption is shown in the Supporting Information. 

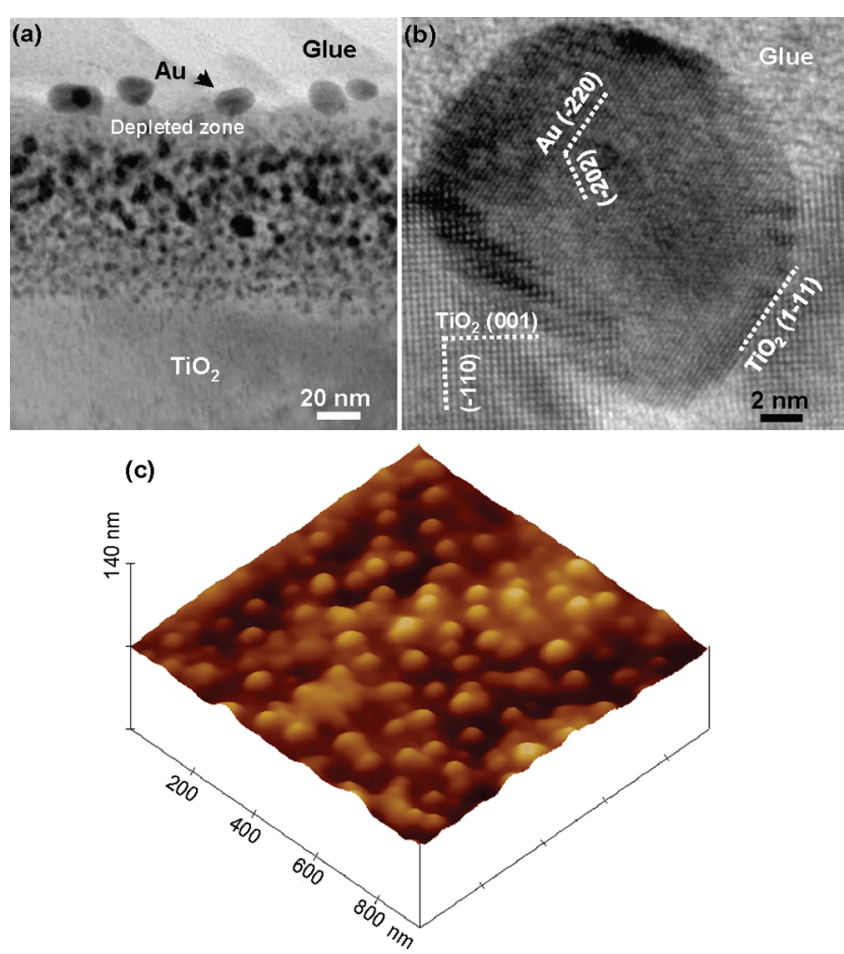

Figure 2. Structure and distribution of $\mathrm{Au}$ particles in the $\mathrm{TiO}_{2}$ host after the $\mathrm{Au}^{+}$ion implantation and subsequent ex situ thermal annealing at $800^{\circ} \mathrm{C}$ for $1 \mathrm{~h}$ in a furnace. (a) Low-magnification crosssectional TEM micrograph. (b) HRTEM image showing a gold hemisphere. (c) AFM image.

The irradiation by low-energy ions has a very limited ion mixture in the host ${ }^{34}$ (e.g., the irradiation with $5 \mathrm{keV} \mathrm{Ga}^{+}$has a peak Ga concentration of only 2 atom $\%){ }^{35}$ In this study, the preferential sputtering of $\mathrm{Au}$ over $\mathrm{TiO}_{2}$ by the low-energy 5 $\mathrm{keV} \mathrm{Ga}{ }^{+}$ions was utilized to decrease the size of the $\mathrm{Au}$ hemispheres continuously (Figure $3 \mathrm{a}-\mathrm{f}$ ). The sputtering yield of $\mathrm{Au}$ under the irradiation of $5 \mathrm{keV} \mathrm{Ga}^{+}$ions can be calculated to be 10.0 atoms/ion, which is significantly larger than that for $\mathrm{TiO}_{2}$ (0.7 for $\mathrm{Ti}, 3.0$ for $\mathrm{O}$ ). This situation is similar to the sputtering effect during the implantation by high-energy ions (e.g., $40.0(\mathrm{Au})$ vs $2.9(\mathrm{Ti})$ and $8.6(\mathrm{O})$ atoms/ion for $260 \mathrm{keV}$ $\mathrm{Au}^{+}$ions). The average diameter of the large $\mathrm{Au}$ particles was measured and plotted at different sputtering times (Figure $3 \mathrm{~g}$ ). The average diameter before sputtering is $25 \mathrm{~nm}$ (with a standard deviation $3.4 \mathrm{~nm}$ ), consistent with the observations by TEM. The particle density measured by SEM is $1.21 \times 10^{10}$ / $\mathrm{cm}^{2}$, close to that of the measurements obtained by AFM. As the irradiation time increases, the average diameter of $\mathrm{Au}$ particles decreases. At $100 \mathrm{~s}$, the average diameter decreases to $7 \mathrm{~nm}$ with a standard deviation of $1.1 \mathrm{~nm}$, suggesting that the large particles maintain good uniformity in size during the sputtering. Because of the resolution limit of the SEM, it is difficult to measure a particle size below $7 \mathrm{~nm}$, although it should be possible to have smaller sizes with longer irradiation times. Although the particle size decreases, the particle density (or the interval between large particles) remains constant during sputtering. This further confirms that it is the $\mathrm{Ga}^{+}$ irradiation that causes the gradual decrease in the size of the nanoparticles on the surface. Because of the significant difference in sputtering yields, $\mathrm{Ga}^{+}$irradiation results in a rapid decrease in the size of $\mathrm{Au}$ particles but there is no apparent change in the thickness of the $\mathrm{TiO}_{2}$ host.
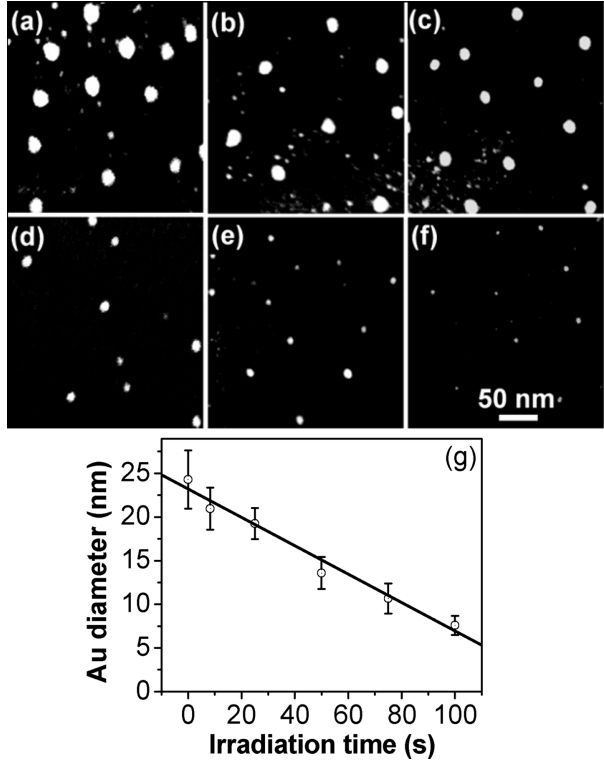

Figure 3. SEM images showing the size-change sequence of $\mathrm{Au}$ nanoparticles half-embedded on the $\mathrm{TiO}_{2}$ surface (a) before and after $\mathrm{Ga}^{+}$sputtering at (b) 8, (c) 25, (d) 50, (e) 75, and (f) $100 \mathrm{~s}$ in Nova FIB operated at $5 \mathrm{kV}$ with a current of $0.12 \mathrm{nA}$. (g) The average diameters of large $\mathrm{Au}$ nanoparticles and the corresponding standard deviation at different sputtering times. The implanted specimen was thermally annealed in a furnace before ion sputtering.

Upon the irradiation of energetic ions, the knocked-out atoms from the embedded metal nanoclusters can diffuse over a distance in the oxide and form satellite nanopartices around the original nanoclusters. ${ }^{36,37}$ The atom loss in the nanoclusters results in the size decrease of the center nanoclusters. ${ }^{38}$ As compared to the fully embedded Au particles, the sputtering effect of the exposed Au hemispheres should be more intense. Furthermore, the nuclear contribution of the energy loss $\left(S_{n}\right)$ for $5 \mathrm{keV} \mathrm{Ga}^{+}$is significantly larger than the electronic contribution $\left(S_{\mathrm{e}}\right)$ within the entire penetration range of $\sim 7 \mathrm{~nm}$. The high ratio $S_{\mathrm{n}} / S_{\mathrm{e}}(\sim 5)$ would also significantly contribute to the sputtering and size decrease of the Au hemispheres. ${ }^{37}$ However, the sizes of satellites are smaller upon irradiation with a reduced $S_{n}$ at a lower energy of ions. ${ }^{39}$ As a result, the sizes of the satellites for the $\mathrm{Ga}^{+}$of only $5 \mathrm{keV}$ would be too small to be detected by the SEM if the satellites could form during the sputtering. The SEM images in Figure 3 have provided some information on the morphological changes in Au particles after the Ga sputtering. To confirm the compositional and morphological changes after the sputtering, cross-sectional TEM images similar to those in Figure 2a would be interesting. Unfortunately, the size of the modified region after the $\mathrm{Ga}$ sputtering in a FIB is only several tens of micrometers, which is too small to make a cross-sectional sample. Similarly, for many applications of the nanocomposites it requires a large modified area. However, current ion implanters, usually capable of handling a broad range of ion types and energies, provide a promising means of synthesizing nanocrystals of a specific size on oxides over a large area by combining high-energy ion implantation and low-energy sputtering.

In situ studies of the thermally induced formation and growth mechanism of $\mathrm{Au}$ nanocrystals in $\mathrm{TiO}_{2}$ provide a perspective by which one may understand the fundamental processes that occur during ion implantation and ion sputtering (Figure 4). During the high-energy ion implantation, the 


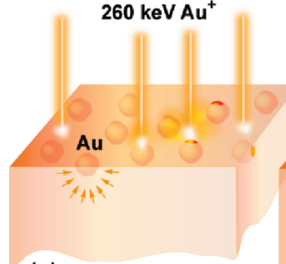

(a)

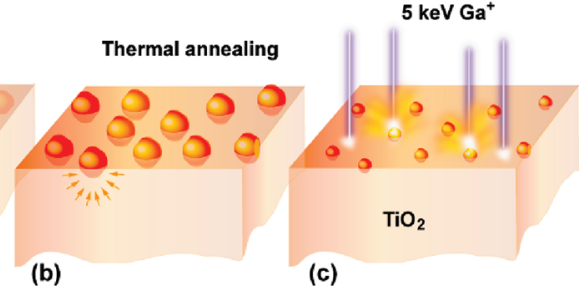

(b) (c)
Figure 4. Fabrication of Au nanocrystals with controlled structure and particle size. (a) Implantation with high-energy ions. (b) Thermal annealing. (c) Preferential sputtering of Au over $\mathrm{TiO}_{2}$ by low-energy ions.

positive $\mathrm{Au}^{+}$ions tend to form neutrally charged $\mathrm{Au}^{0}$ as the negative electron coming from the conductive base of the ion implanter. The coarsening of $\mathrm{Au}$ clusters due to irradiationenhanced diffusion competes with the decreasing particle size caused by the surface sputtering, resulting in the formation of $\mathrm{Au}$ clusters that are fully embedded in the region near the top surface of $\mathrm{TiO}_{2}$ (Figure 4a). Without the sputtering, the thermally enhanced diffusion during annealing causes the formation of half-embedded $\mathrm{Au}$ nanocrystals on the surface because of the preferential growth of $\mathrm{Au}$ particles toward the top surface (Figure $4 \mathrm{~b}$ ). The preferential sputtering of Au over $\mathrm{TiO}_{2}$ by low-energy ions causes the decreasing size of the halfembedded $\mathrm{Au}$ nanocrystals (Figure 4c). The Supporting Information provides detailed explanations of these processes. With the ion implantation and subsequent thermal processing or further ion sputtering, the important properties of the nanocomposite can be optimized for a particular application by controlling the location and average size of the precipitates.

\section{CONCLUSIONS}

In situ thermal annealing was used to observe Au nanoparticles directly, which were initially fully embedded in $\mathrm{TiO}_{2}$, grew, and become exposed at the surface as a result of the localized absorption of nearby smaller particles and the preferential growth of Au particles toward the surface. The precise control of the size of the half-embedded Au nanoparticles from 25 to 7 $\mathrm{nm}$ was achieved by the preferential sputtering of Au over the $\mathrm{TiO}_{2}$ host by low-energy ions. This method can be used to control the structure and size of a wide variety of nanoparticles in a matrix where the surface structure and particle size are required to obtain specific material properties.

\section{ASSOCIATED CONTENT}

\section{S Supporting Information}

Highly localized absorption and formation of a gold-depleted zone. Fundamental processes that occur during ion implantation, thermal annealing, and ion sputtering. This material is available free of charge via the Internet at http://pubs.acs.org.

\section{AUTHOR INFORMATION}

\section{Corresponding Author}

*E-mail: rodewing@umich.edu. Fax: +1 734647 5706. Tel: +1 7347639295.

\section{ACKNOWLEDGMENTS}

The funding for this study was provided by the Office of Basic Energy Sciences of the U.S. DOE (DE-FG02-97ER45656).

\section{REFERENCES}

(1) Rodriguez, J. A.; Ma, S.; Liu, P.; Hrbek, J.; Evans, J.; Perez, M. Science 2007, 318, 1757-1760.

(2) Haruta, M.; Yamada, N.; Kobayashi, T.; Iijima, S. J. Catal. 1989, $115,301-309$.

(3) Bamwenda, G. R.; Tsubota, S.; Nakamura, T.; Haruta, M. Catal. Lett. 1997, 44, 83-87.

(4) Subramanian, V.; Wolf, E. E.; Kamat, P. V. Langmuir 2003, 19, 469-474.

(5) Tsuji, H.; Sugahara, H.; Gotoh, Y.; Ishikawa, J. Nucl. Instrum. Methods Phys. Res., Sect. B 2003, 206, 249-253.

(6) Campbell, C. T. Science 2004, 306, 234-235.

(7) Heitmann, J.; Muller, F.; Zacharias, M.; Gosele, U. Adv. Mater. 2005, 17, 795-803.

(8) Honda, S.; Modine, F. A.; Meldrum, A.; Budai, J. D.; Haynes, T. E.; Boatner, L. A. Appl. Phys. Lett. 2000, 77, 711.

(9) Shi, D. L.; Lian, J.; Wang, W.; Liu, G. K.; He, P.; Dong, Z. Y.; Wang, L. M.; Ewing, R. C. Adv. Mater. 2006, 18, 189.

(10) Shi, D. L.; Cho, H. S.; Chen, Y.; Xu, H.; Gu, H.; Lian, J.; Wang, W.; Liu, G.; Huth, C.; Wang, L. M.; Ewing, R. C.; Budko, S.; Pauletti, G. M.; Dong, Z. Adv. Mater. 2009, 21, 2170-2173.

(11) Meldrum, A.; Haglund, R. F.; Boatner, L. A.; White, C. W. Adv. Mater. 2001, 13, 1431-1444.

(12) Haruta, M.; Tsubota, S.; Kobayashi, T.; Kageyama, H.; Genet, M. J.; Delmon, B. J. Catal. 1993, 144, 175-192.

(13) Haruta, M. CATTECH 2002, 6, 102-115.

(14) Michalet, X.; Pinaud, F. F.; Bentolila, L. A.; Tsay, J. M.; Doose, S.; Li, J. J.; Sundaresan, G.; Wu, A. M.; Gambhir, S. S.; Weiss, S. Science 2005, 307, 538 .

(15) Stepanov, A. L.; Popok, V. N. Surf. Sci. 2004, 566-568, 12501254.

(16) Meldrum, A.; White, C. W.; Boatner, L. A.; Anderson, I. M.; Zuhr, R. A.; Sonder, E.; Budai, J. D.; Henderson, D. O. Nucl. Instrum. Methods Phys. Res., Sect. B 1999, 148, 957.

(17) Bokhimi, X.; Zanella, R. J. Phys. Chem. C 2007, 111, 2525-2532.

(18) Cuenat, A.; George, H. B.; Chang, K. C.; Blakely, J. M.; Aziz, M. J. Adv. Mater. 2005, 17, 2845.

(19) Lian, J.; Wang, L. M.; Sun, X.; Yu, Q.; Ewing, R. C. Nano Lett. 2006, 6, 2637.

(20) Wei, Q.; Lian, J.; Lu, W.; Wang, L. M. Phys. Rev. Lett. 2008, 100, 076103.

(21) Tom, R. T.; Nair, A. S.; Singh, N.; Aslam, M.; Nagendra, C. L.; Philip, R.; Vijayamohanan, K.; Pradeep, T. Langmuir 2003, 19, 34393445.

(22) Fromknecht, R.; Linker, G.; Wang, L. M.; Zhu, S.; Sun, K.; Veen, A. v.; Huis, M. v.; Niemeyer, J.; Weimann, T.; Wang, J. Surf. Interface Anal. 2004, 36, 193-194.

(23) Kishimoto, N.; Umeda, N.; Takeda, Y.; Gritsyna, V. T.; Renk, T. J.; Thompson, M. O. Vacuum 2000, 58, 60-78.

(24) Ramaswamy, V.; Haynes, T. E.; White, C. W.; MoberlyChan, W. J.; Roorda, S.; Aziz, M. J. Nano Lett. 2005, 5, 373.

(25) White, C. W.; Budai, J. D.; Zhu, J. G.; Withrow, S. P.; Aziz, M. J. Appl. Phys. Lett. 1996, 68, 2389.

(26) Tsuji, H.; Ishikawa, J.; Itoh, H.; Toyota, Y.; Gotoh, Y. Appl. Surf. Sci. 1996, 100-101, 342-346.

(27) Tsuji, H.; Kido, S.; Sasaki, H.; Gotoh, Y.; Ishikawa, J. Rev. Sci. Instrum. 2000, 71, 804.

(28) Zhu, S.; Sun, K.; Wang, L. M.; Ewing, R. C.; Fromknecht, R. Nucl. Instrum. Methods Phys. Res., Sect. B 2006, 242, 152-156.

(29) SRIM 2011, http://www.srim.org/SRIM/SRIM2011.htm.

(30) Li, W. X.; Wang, L. M.; Lang, M.; Trautmann, C.; Ewing, R. C. Earth Planet. Sci. Lett. 2011, 302, 227-235.

(31) Li, W. X.; Wang, L. M.; Sun, K.; Lang, M.; Trautmann, C.; Ewing, R. C. Phys. Rev. B 2010, 82, 144109.

(32) Budai, J. D.; White, C. W.; Withrow, S. P.; Chisholm, M. F.; Zhu, J.; Zuhr, R. A. Nature 1997, 390, 384-386.

(33) Voorhees, P. W. Annu. Rev. Mater. Sci. 1992, 22, 197-215.

(34) Mayer, J.; Giannuzzi, L. A.; Kamino, T.; Michael, J. MRS Bull. 2007, 32, 400-407. 
(35) Thompson, K.; Gorman, B.; Larson, D. J.; van Leer, B.; Hong, L. Microsc. Microanal. 2006, 12, 1736-1737.

(36) Cesca, T.; Pellegrini, G.; Bello, V.; Scian, C.; Mazzoldi, P.; Calvelli, P.; Battaglin, G.; Mattei, G. Nucl. Instrum. Methods Phys. Res., Sect. B 2010, 268, 3227-3230.

(37) Mattei, G.; De Marchi, G.; Maurizio, C.; Mazzoldi, P.; Sada, C.; Bello, V.; Battaglin, G. Phys. Rev. Lett. 2003, 90, 085502.

(38) Rizza, G.; Cheverry, H.; Gacoin, T.; Lamasson, A.; Henry, S. J. Appl. Phys. 2007, 101, 014321.

(39) Mattei, G.; Battaglin, G.; Bello, V.; De Marchi, G.; Maurizio, C.; Mazzoldi, P.; Parolin, M.; Sada, C. J. Non-Cryst. Solids 2003, 322, 1721. 